\title{
Impact of COVID-19 pandemic on postgraduate medical education - a survey of UK trainees
}

\author{
Authors: Patience Ehilawa, ${ }^{\mathrm{A}}$ Fiona Thompson, ${ }^{\mathrm{B}}$ Rana Ahmed, ${ }^{\mathrm{A}}$ Mary Ariyo, ${ }^{\mathrm{A}}$ Sarah Muldoon, ${ }^{\mathrm{C}}$ Paul Sadler ${ }^{\mathrm{D}}$ and \\ Jonathan Corne ${ }^{E}$
}

Fig 1. Specialty of respondents in medicine $(n=342)$.

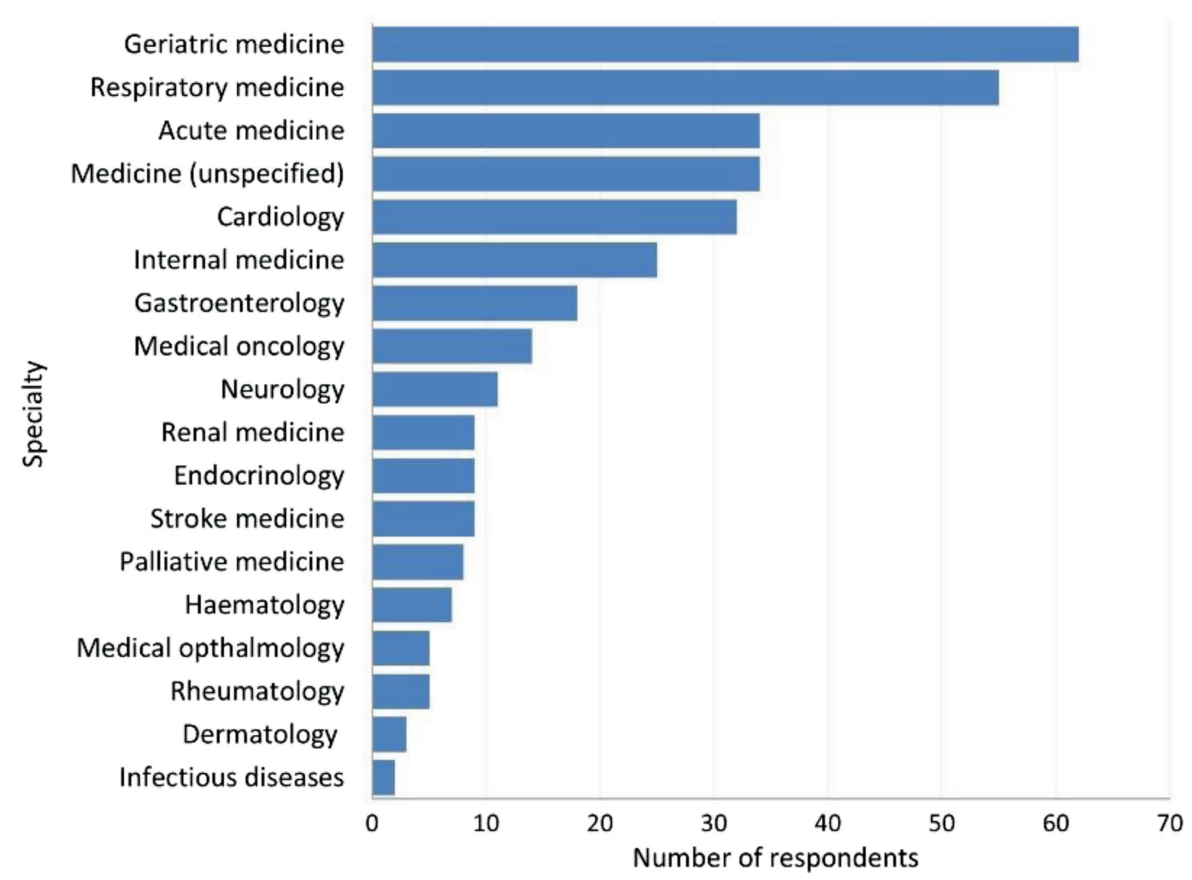

\section{Introduction}

The COVID-19 pandemic has caused significant disruption to patient care delivery and medical training in the UK. ${ }^{1}$ However, the views of healthcare professionals on the impact of the pandemic has not been fully explored. This study aimed to identify the challenges experienced by healthcare professionals during the COVID-19 pandemic and proffer potential solutions, from the perspectives of postgraduate trainees.

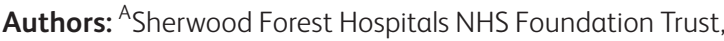
Sutton in Ashfield, UK; ${ }^{B}$ Portsmouth Hospitals NHS Trust, Portsmouth, UK: CKing's College Hospital NHS Foundation Trust, London, UK; ${ }^{D}$ Health Education England - Wessex, UK; ${ }^{\text {Health }}$ Education England - East Midlands, UK

\section{Methods}

A SurveyMonkey ${ }^{\circledR}$ questionnaire was emailed to postgraduate trainees through Health Education England (HEE) deanery databases, to capture their experiences during the pandemic. The survey was also circulated informally via WhatsApp ${ }^{\circledR}$, to include the views of individuals in non-training posts. Ethics review was not required. Data collection is ongoing and is projected to continue until February 2021. Preliminary findings are presented.

\section{Results and discussion}

A total of 828 responses were received between July and September 2020: 45\% from East Midlands, 44\% from Wessex, $5 \%$ from West Midlands and 6\% from 'other' deaneries. Over two-thirds of respondents were trainees in medicine $(n=342)$, surgery $(n=105)$ and general practice (GP; $n=97)$. The distribution of respondents according to (sub)specialties in medicine is outlined in Fig 1. The majority of respondents were junior doctors below 
registrar grade (50\%), followed by registrars (37\%), GP trainees (11\%), advanced clinical practitioners / physician associates $(0.6 \%)$, dental trainees $(0.6 \%)$, associate specialists/post-CCT fellows $(0.4 \%)$ and 'others' $(0.4 \%) .44 \%$ of respondents $(n=365)$ stated that they were redeployed outside their usual area of practice; predictably to acute/general medicine (28\%), 'COVID wards' / palliative wards $(20 \%)$, critical care $(18 \%)$, respiratory medicine (9\%) and emergency medicine $(8 \%)$.

Analysis of free-text responses identified five key challenges experienced during the pandemic. 1) 'Communication barriers' attributed to personal protective equipment (PPE) and social distancing. 2) 'Uncertainty and constant change' in patient pathways, guidelines, policies and PPE. 3) 'Rota difficulties' due to intensity of on-call shifts and staffing. 4) 'Interrupted training', particularly missed procedural skills and exam cancellations. 5) 'Emotional burden' of working in a pandemic with associated feelings of helplessness, anxiety and stress. Other challenges are presented in Fig 2.

Proposed solutions from trainees include the following. 1) Create regional virtual teaching platforms to replace cancelled teaching. 2) Provide clear channels of communication and regular virtual updates with accountable bodies. 3) 'Flexibility' with appraisals, clinical rotations and study leave allowances. 4) Provide formally approved alternatives for achieving curriculum competencies such as recognition of remote consultations towards clinic attendance targets and optimising clinical skills training facilities. 5) Avoid 'forceful' or 'unfair' redeployment and ensure 'prompt' and explicit communication about the redeployment process. 6) Provide wellbeing support to minimise 'burnout' of frontline staff and effects of social isolation for staff who are 'shielding'.

\section{Conclusion}

This survey highlights the challenges created by the pandemic, notably the disruption to education and training, and the (potentially) adverse impact on the personal lives and psychosocial wellbeing of healthcare professionals. It is anticipated that the proposed solutions would prove valuable to relevant stakeholders in the ongoing efforts to transition back to 'normal' services.

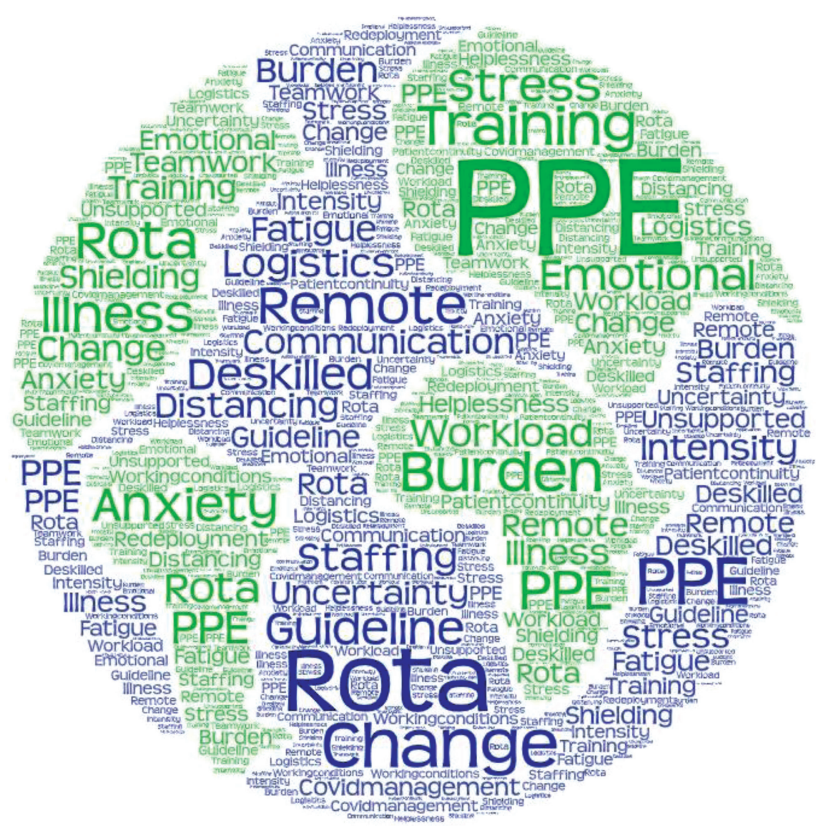

Fig 2. Word cloud of challenges experienced during the pandemic. Designed using a template from https://wordart.com

\section{Conflicts of interest}

None declared.

\section{Reference}

1 AoMRC Four Nation The Need to Reinstate Training and Services. Conference of Postgraduate Medical Deans (UK), 2020. www. copmed.org.uk/images/docs/AoMRC_Four_Nation_The_need_ to_reinstate_training_3_June_2020.pdf [Accessed 11 September 2020]. 